\title{
Possibilities for Estimating the Heights of Volcanic Ash Plumes in the Information System of Remote Monitoring of the Activity of Kamchatka and Kuril Volcanoes "VolSatView"
}

\author{
Alexey A. Bril, Alexandr V. Kashnitskii, Ivan A. Uvarov \\ Space Research Institute, Russian Academy of Sciences, Moscow, Russia \\ bril@d902.iki.rssi.ru
}

\begin{abstract}
The work is devoted to the problem of obtaining estimates of the height of ash, which was erupted into the atmosphere as a result of an explosive eruption of a volcano, using satellite data. The main ways to solve the problem are described. The work describes the possibilities of estimating the height of a volcanic ash cloud based on various satellite data in the information system of remote monitoring of the activity of volcanoes "VolSatView". Two possibilities are described for obtaining an estimate of the heights of top cloud of ash: an estimate using meteorological forecast data and an estimate based on a comparison of observations from loworbit and geostationary satellite systems. It is told about the main advantages and disadvantages of the implemented methods. An estimate of the measurement accuracy of the described technologies is also given.
\end{abstract}

Keywords: remote sensing, satellite data, information systems, «VolSatView», explosive eruptions, volcanoes, ash, ash plume, height of cloud, monitoring of the activity of volcanoes 


\title{
ВОЗМОЖНОСТИ ОЦЕНКИ ВЫСОТ ПЕПЛОВЫХ ШЛЕЙФОВ ВУЛКАНОВ В ИНФОРМАЦИОННОЙ СИСТЕМЕ ДИСТАНЦИОННОГО МОНИТОРИНГА АКТИВНОСТИ ВУЛКАНОВ КАМЧАТКИ И КУРИЛ «VOLSATVIEW»
}

\author{
А.А. Бриль, А.В. Кашниикий, И.А. Уваров \\ Институт космических исследований РАН, Москва, Россия \\ bril@d902.iki.rssi.ru
}

\begin{abstract}
Работа посвящена проблеме получения по спутниковым данным оценки высоты вулканического пепла, на которую он был выброшен в атмосферу в результате эксплозивного извержения вулкана. Сделан краткий обзор основных существующих способов решения этой задачи. Рассказано о разработанных в информационной системе дистанционного мониторинга активности вулканов «VolSatView» возможностях оценки высоты облака вулканического пепла на основе спутниковых данных различных систем. А именно, описаны возможности получения оценки высот верхней границы пепловых облаков: оценка с использованием данных метеорологических прогнозов и оценка на основе сравнения наблюдений с низкоорбитальных и геостационарных спутниковых систем. Рассказано об основных преимуществах и недостатках реализованных методов. В заключение приводится оценка их точности.
\end{abstract}

Ключевые слова: дистанционное зондирование, спутниковые данные, информационная система, «VolSatView», эксплозивные извержения, вулканы, пепел, пепловый шлейф, высота облака, мониторинг активности вулканов

\section{Введение}

Эксплозивные извержения вулканов являются одними из опаснейших природных явлений. По данным вулканологов, ежегодно, из 36 действующих вулканов Камчатки и Северных Курил, от трех до восьми из них находятся в состоянии извержения или активизации [1]. Продукт таких явлений, вулканический пепел, представляет большую опасность, как для окружающей среды, так и для многих сфер деятельности человека, в том числе для авиации. Облака вулканического пепла, выброшенного в атмосферу на высоту до 8-15 км над уровнем моря, могут распространяться на огромные расстояния от самого центра извержения, сильно влияя на безопасность полетов в зоне распространения пепла. Поэтому, задачи своевременного обнаружения, комплексного анализа и прогноза распространения облаков вулканического пепла являются одними из главных задач мониторинга вулканов. В том числе для решения такого рода задач была создана и эксплуатируется информационная система «Дистанционный мониторинг активности вулканов Камчатки и Курил (VolSatView)»[2]. Одним из основных параметров, необходимых для анализа облаков вулканического пепла, является высота, на которую он был выброшен в атмосферу и на которой распространяется. На данный момент существует множество способов оценки высоты пепловых облаков. В данной работе мы кратко рассмотрим некоторые из них, и представим возможности реализованных в информационной системе «VolSatView» методов получения оценки высоты, а также приведем анализ их точности. 


\section{Основные способы дистанционной оценки высот пепловых облаков}

Прежде, чем приступить к описанию методов оценки высоты облаков вулканического пепла, реализованных в информационной системе «VolSatView», стоит описать основные известные способы решения поставленной задачи. Работы по изучению высоты пепловых шлейфов ведутся не одно десятилетие. В настоящее время широко известны следующие методы оценивания высоты пеплового облака по спутниковым данным: лидарный метод, метод корреляции ветра, метод параллакса и метод оценки температуры верхней границы пеплового облака («температурный» метод). Отметим, что кроме указанных, применяются и другие методы оценки высоты пепла, но уже с использованием наземных измерений. Например, в данной работе для анализа точности нами будут использованы данные о высоте пепла, полученные на основе снимков наземных веб-камер.

Одним из наиболее точных методов получения высоты пеплового облака является лидарный метод. Именно оценки высот, полученных данным методом, часто используются в качестве проверочных данных для других методов оценки [3]. Тем не менее, нерегулярность поступления данных лидаров и их ограниченный пространственный охват делают данный метод непригодным для оперативного получения оценок высот для каждого конкретного извержения.

Еще одним достаточно точным методом получения высоты пеплового облака является метод корреляции ветра. Метод состоит в том, чтобы сопоставить скорость и направление пеплового шлейфа с профилем скорости и направления ветра в определенных слоях атмосферы [4],[5]. Несмотря на простоту идеи, в основе которой лежит данный метод, сложность его реализации делает затруднительным использование метода корреляции ветра для получения оперативной оценки высоты. Основная сложность реализации данного метода состоит в том, что необходимо достаточно точно определять направление и скорость движения пеплового шлейфа по спутниковому изображению. Кроме того, также требуется, чтобы профиль ветра был известен и достаточно изменчив для различных слоев атмосферы.

В отличие от метода корреляции ветра, для «температурного» метода требуется гораздо меньше вспомогательных данных. Суть этого метода состоит в нахождении по метеорологическому профилю такой температуры, которая соответствует температуре облака вулканического пепла. Наконец, метод параллакса основан на эффекте, когда положение объекта относительно удаленного фона изменяется в зависимости от положения наблюдателя. Существуют различные реализации метода параллакса, например, оценка по стереопаре или по положению тени от облака.

При выборе методов оценки высоты пепла, которые будут включены в информационную системе «VolSatView», авторы руководствовались, в первую очередь, решаемыми ей задачами. А именно, необходимо было реализовать такие возможности оценки высоты пепла, с помощью которых специалисты-вулканологи смогут достаточно просто получать такие оценки в максимально широком диапазоне погодных условий, в дневное и ночное время, с максимально высокой оперативностью. В связи с этим, например, лидарный метод не подходит из-за нерегулярности поступления данных. В результате авторами были выбраны и реализованы «температурный» метод и метод сравнения наблюдений с низкоорбитальных и геостационарных спутниковых систем на основе эффекта параллакса. Особенности этой реализации в информационной системе «VolSatView» будут подробно описаны далее.

\section{Реализованные в системе VolSatView методы оценки высоты}

На данный момент в информационную систему внедрены два основных метода оценки высоты облака вулканического пепла: «температурный» метод с использованием метеорологических данных и спутниковой информации и метод, основанный на сравнении наблюдений, получаемых по данным геостационарных и низкоорбитальных спутников с разных 
углов съемки. Имеется возможность оценки высот пепловых шлейфов на основе спутниковых данных TERRA, AQUA (прибор MODIS), Suomi NPP (прибор VIIRS), HIMAWARI-8 (прибор AHI), METEOR-M2 (прибор MSU-MR), NOAA (прибор AVHRR) и других, предоставляемых Центром Коллективного Пользования (ЦКП) «ИКИ-Мониторинг» [6].

В 2017-ом году в информационную систему был внедрен «температурный» метод. Исследования по оценке высоты пеплового шлейфа с использованием инфракрасных каналов спутниковых данных велись еще в 1980-ых годах [7]. Алгоритм поиска высоты пепловых облаков по «температурному» методу основан на предположении, что радиояркостная температура соответствует температуре атмосферы на определенной высоте. По тепловому каналу имеющихся спутниковых данных находится радиояркостная температура верхней границы пеплового облака. По профилю температур и высот из метеоданных выбирается такой интервал температур, которому принадлежит полученная по спутниковым данным радиояркостная температура. Предполагается, что высота верхней границы пеплового облака соответствует высоте в нижней границе найденного интервала температур.

Основным недостатком данного метода является грубое допущение, что радиояркостная температура в тепловом канале спутниковых данных соответствует температуре воздуха в различных слоях атмосферы. К тому же, для получения оценки по данному методу требуется наличие атмосферных профилей высокой точности, которые часто бывают недоступны. Кроме того, если облако вулканического пепла не является непрозрачным, а под верхним слоем пепла находятся многослойные метеорологические облака, то в таком случае полученные радиояркостные температуры могут быть сильно завышены, что приведет к занижению оценки высоты. Наконец, для высоких облаков вблизи тропопаузы метод также подвержен ошибкам, поскольку скорость изменения температуры с высотой мала [7].

В 2018-ом году в информационной системе «VolSatView» был реализован метод сравнения наблюдений с низкоорбитальных и геостационарных спутниковых систем, «метод стереопары». Основой алгоритма получения оценки высоты пеплового облака по данному методу является эффект параллакса. Облако на определенной высоте над поверхностью Земли имеет разные координаты на снимке с геостационарного и низкоорбитального спутников. На Рис. 1 приведен пример изображения, на котором показано одно и то же пепловое облако, снятое двумя различными спутниками в один момент времени. Для получения оценки высоты на полученных данных низкоорбитального спутника и ближайшим по времени к ним данным геостационарного спутника выбирается одна и та же точка на верхней границе пеплового облака и вычисляются ее геодезические координаты с разных углов съемки - низкоорбитального и геостационарного спутников. Далее, по орбитальным параметрам спутниковых систем с использованием упрощенной модели движения SGP4 [8] находится точное положение низкоорбитального и геостационарного спутников в момент съемки. Путем пересечения плоскости съемки низкоорбитального и направления съемки геостационарного спутников получаются геоцентрические координаты точки на верхней границе пеплового облака. Выполнив преобразование из геоцентрических координат в геодезические, получаем высоту точки на верхней границе пеплового облака над поверхностью земного эллипсоида.

В отличие от метода оценки высоты по метеорологическому профилю, метод «стереопары» является чисто геометрическим, поэтому получаемая оценка высоты является более точной. Основным же недостатком данного метода является то, что на данный момент эксперту-вулканологу необходимо подбирать точки пеплового облака на двух изображениях путем визуальной оценки, что порой весьма затруднительно. 


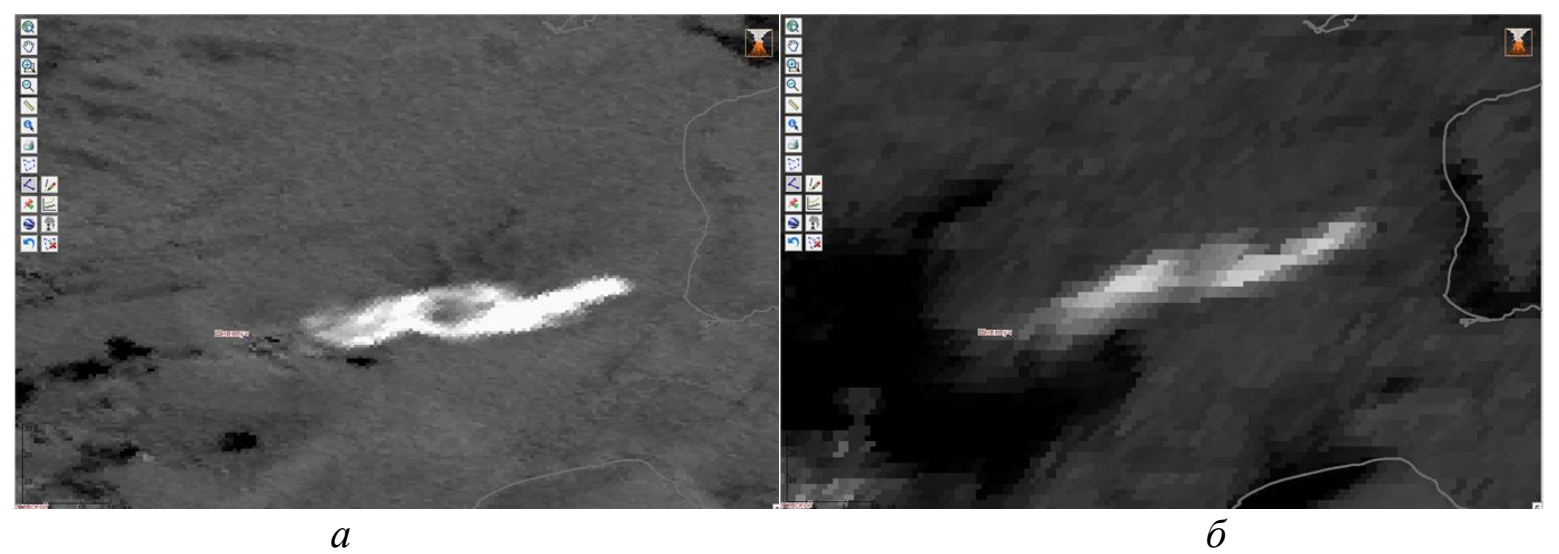

Pис.1. Облако вулканического пепла, вулкан Шивелуч, время события 24 мая 2017 года 21:50:00. а) данные со спутника NOAA, б) данные со спутника HIMAWARY-8

\section{Заключение}

В заключение приведем анализ точности полученных высот пепловых облаков по реализованным в информационной системе VolSatView методам. Из базы данных Камчатской группы реагирования на вулканические извержения KVERT (http://www.kscnet.ru/ivs/kvert/), [9] было выбрано 20 эсплозивных событий, по которым имелись оценки высоты, полученные с вебкамер. Для каждого события в системе VolSatView подбирались доступные спутниковые данные и оценивалась высота верхней границы пеплового облака каждым описанным выше методом. В приведенной ниже таблице 1 представлены результаты такой оценки высоты верхней границы облака в метрах над уровнем моря для восьми эксплозивных событий. Как видно, оценки высот, полученные методом стереоскопического сопоставления, являются более точными при сравнении с проверочными данными веб-камер. Однако окончательный вывод о точности затрудняется отсутствием точных и объективных данных о высоте пеплового облака, особенно при его удалении от вулкана, а также трудностью в интерпретации высоты, особенно когда разные части облака находятся на разной высоте.

Таблица.1. Результаты оценки высоты верхней границы облака в метрах над уровнем моря для восьми эксплозивных событий

\begin{tabular}{|c|c|c|c|c|}
\hline Вулкан & Время события & Данные KVERT & $\begin{array}{l}\text { "Температурный» } \\
\text { метод }\end{array}$ & Стереопара \\
\hline Ключевской & 20.08 .2017 & $7000 \mathrm{~m}$. & $5191 \mathrm{M.}$ & $6000-6800 \mathrm{M}$. \\
\hline Безымянный & 09.03.2017 & $6000-7000$ м. & $4500 \mathrm{~m}$. & $6000-6400$ м. \\
\hline Шивелуч & 15.06.2017 & $6000-6500$ м. & $3700 \mathrm{~m}$. & $4000-6300$ м. \\
\hline Шивелуч & 28.02.2015 & $8000-9000$ м. & 7989 м. & $7500-8500$ м. \\
\hline Шивелуч & 25.05.2017 & $4000 \mathrm{M}$. & $1700 \mathrm{~m}$. & $2900-3600$ м. \\
\hline Шивелуч & 24.05.2017 & $9000-10000$ м. & 6673 м. & $10000-11000 \mathrm{~m}$. \\
\hline Шивелуч & 04.12 .2017 & $2500-4000$ м. & $10001 \mathrm{M}$. & $3500-5500 \mathrm{M}$ \\
\hline Шивелуч & 16.05 .2017 & Нет данных & 9974 м. & $5000-6000$ м. \\
\hline
\end{tabular}

Разработанный на сегодня в системе дистанционного мониторинга активности вулканов Камчатки и Курил «VolSatView» функционал позволяет в оперативном режиме проводить оценку высоты пепловых шлейфов по различным имеющимся в системе спутниковым данным. Особо отметим, для использования этого функционала нет необходимости в дополнительном программной обеспечении, заказе и скачивании спутниковых данных, выполнении сложных обработок, для доступа необходим только веб-браузер. Наличие подобных возможностей значительно упрощает решение различных задач по мониторингу вулканической активности.

Работа выполнена при поддержке Российского научного фонда (проект № 16-17-00042). При оценке высоты пепловых шлейфов также использовались возможности Центра 
коллективного пользования ИКИ-Мониторинг, развиваемого при поддержке ФАНО (тема «Мониторинг», госрегистрация №01.20.0.2.00164).

\section{References}

[1] Girina O.A., Loupian E.A., Sorokin A.A., Melnikov D.V., Romanova I.M., Kashnitskii A.V., Uvarov I.A., Malkovsky S.I., Korolev S.P., Manevich A.G., Kramareva L.S., Comprehensive monitoring of explosive volcanic eruptions of Kamchatka, Petropavlovsk-Kamchatsky: IVS DVO RAS. p. 192.

[2] Gordeev E.I., Girina O.A., Lupyan E.A., Sorokin A.A., Kramareva L.S., Efremov V.Yu., Kashnitskii A.V., Uvarov I.A., Burtsev M.A., Romanova I.M., Melnikov D.V., Manevich A.G., Korolev S.P., Verkhoturov A.L., The VolSatView information system for Monitoring the Volcanic Activity in Kamchatka and on the Kuril Islands, J. Volcanalog. Seismol., 2016, 10: 382. DOI: 10.1134/S074204631606004X.

[3] Pavolonis M.J., A.K. Heidinger, and J.Sieglaff, Automated retrievals of volcanic ash and dust cloud properties from upwelling infrared measurements, J.Geophys. Res. Atmos., 2013, 118, 1436-1458. DOI:10.1002/jprd.50173.

[4] Holasek, R. E., S. Self, and A. W. Woods, Satellite observations and interpretation of the 1991 Mount Pinatubo eruption plumes, J. Geophys. Res., 1996, 101, 27,635-27,655, DOI:10.1029/96JB01179.

[5] Tupper, A., S. Carn, J. Davey, Y. Kamada, R. Potts, F. Prata, and M. Tokuno, An evaluation of volcanic cloud detection techniques during recent significant eruptions in the western 'Ring of Fire', Remote Sens. Environ., 2004, 91, 27-46.

[6] Loupian E.A., Proshin A.A., Burtsev M.A., Balashov I.V., Bartalev S.A., Efremov V.Yu., Kashnitskiy A.V., Mazurov A.A., Matveev A.M., Sudneva O.A., Sychugov I.G., Tolpin V.A., Uvarov I.A., IKI center for collective use of satellite data archiving, processing and analysis systems aimed at solving the problems of environmental study and monitoring, Sovremennye problemy distantsionnogo zondirovaniya Zemli iz kosmosa, 2015, 12(5), pp. 263-284.

[7] Prata, A. J., and I. F. Grant, Determination of mass loadings and plume heights of volcanic ash clouds from satellite data, CSIRO Atmos. Res. Tech. Pap., 2001, no. 48.

[8] Hoots, Felix R.; Ronald L. Roehrich. "Models for Propagation of NORAD Element Sets" (PDF). United States Department of Defense Spacetrack Report (3), 1988, Retrieved 16 June 2010.

[9] Girina O.A., Gordeev E.I., KVERT project: reduction of volcanic hazards for aviation from explosive eruptions of Kamchatka and Northern Kuriles volcanoes, Vestnik DVO RAN, 2007, Vol. 132, No. 2, pp. 100-109. 